\title{
Franz Boas: da geografia ratzeliana à antropologia nos Estados Unidos da América
}

\author{
Álvaro Santo Donegá Júnior*, Antonio Carlos Vitte
}

\begin{abstract}
Resumo
A presente pesquisa teve como intuito apresentar a trajetória biográfica do jovem Franz Boas (1858-1942), desde seu nascimento na Alemanha até sua consolidação como um antropólogo nos Estados Unidos, atentando para o seu percurso entre os países ainda no século XIX, momento no qual ocorria a institucionalização tanto da geografia quanto da antropologia enquanto ciências universitárias em ambos os locais. Desse modo, mostrou-se como as suas origens alemãs, sejam pessoais ou acadêmicas, tiveram forte influência na sua vida em terras norte-americanas, uma vez que seus escritos deram continuidade às suas raízes germânicas. Em especial, procurou-se analisar como a antropogeografia proposta por Friedrich Ratzel (1844-1904) reverberou na teoria antropológica boasiana, a qual fez com que Boas, um geógrafo de formação, se consolidasse como o antropólogo fundador da escola norte-americana.
\end{abstract}

\section{Palavras-chave:}

Franz Boas, Friedrich Ratzel, antropogeografia.

\section{Introdução}

Trata-se de uma unanimidade para o pensamento antropológico situar a figura de Franz Boas como o "pai fundador" da escola de antropologia dos Estados Unidos. Dada a sua trajetória pessoal, também se reconhece as suas origens germânicas, porém é pouco ressaltada a importância de suas raízes alemãs para a formação de seu pensamento antropológico. Nesse sentido, a análise de seu percurso biobibliográfico demonstra de que maneira Boas foi herdeiro de uma enorme tradição intelectual da Alemanha do século XIX, marcada na figura de grandes pensadores, dentre os quais, Friedrich Ratzel, cujas ideias antropogeográficas reverberaram no pensamento antropológico boasiano.

\section{Resultados e Discussão}

Franz Uri Boas nasceu no ano de 1858, na pequena cidade de Minden, na província prussiana de Vestfália. Cresceu numa família de comerciantes judeus e entrou para a universidade em 1877, estudando física e geografia em Heidelberg, Bonn e Kiel, sucessivamente. Analisando nos pormenores sua trajetória pessoal durante a década de 80 do século XIX, nota-se que Boas teve contato com os grandes expoentes da geografia e da antropologia alemã da época (STOCKING JR, 1968). Após concluir seus estudos universitários em 1881, já no ano seguinte mudou-se para Berlim para trabalhar sob a orientação do patriarca da antropologia alemã, Adolf Bastian (1826-1905), no Museu do Folclore de Berlim, onde também teve contato com o mestre da antropologia física Rudolf Virchow (1821-1902), com quem estudou técnicas de medição. Concomitantemente, Boas compartilhava com seu antigo professor universitário, o geográfo Theobald Fischer (1846-1910), o desejo de fazer uma expedição científica para a América, tendo em vista seu interesse nos estudos geográficos da região de Baffinland (KOELSCH, 2004). Finalmente, em 1883, depois de prestar seu serviço militar na Alemanha, Boas conseguiu fundos para realizar sua viagem, ao obter recursos de um grande jornal berlinense, o Berliner Tageblatt, em troca de artigos sobre sua experiência em meio dos esquimós (MÜLLER-WILLE, 2014).

Ao mesmo tempo, Ratzel delimitava as bases de sua fundamentação teórica, ao publicar, em 1882, sua obra Anthropogeographie (RATZEL, 1914). Quando Boas, então, realiza sua viagem etnográfica, percebe-se a reverberação das ideias ratzelianas em sua teoria, pois o próprio Boas é explícito em ter o intuito de aplicar o método proposto por Ratzel em um território delimitado (D'ANGLURE, 1984).

Não obstante, Boas se posicionou frente às ideias ratzelianas no embate entre o evolucionismo e o difusionismo que marcou a antropologia de sua época (KUPER, 2005); além de também ter ressaltado a importância de sua formação geográfica para a consolidação de seu pensamento antropológico (BOAS, 1996). Nesse sentido, como herói fundador que alicerçou as bases da antropologia nos Estados Unidos da América, Boas foi herdeiro de uma tradição intelectual alemã e, ademais, não se consolidou como um geógrafo em nenhum dos dois países por motivos fortuitos que acabaram o levando para a antropologia (SPETH, 1978).

\section{Conclusões}

Boas defendia uma postura holística frente à fragmentação disciplinar que caracterizou o período de institucionalização científica tanto na Alemanha quanto nos Estados Unidos no final do século XIX. Nesse sentido, por mais que tenha se consolidado como um antropólogo, Boas nunca deixou de ser também um geógrafo e as marcas germânicas de sua formação são patentes, especialmente da antropogeografia de um de seus mestres, Friedrich Ratzel.

\section{Agradecimentos}

Agradeço ao professor Antonio Carlos Vitte pela atenciosa orientação e aos colegas de graduação dos cursos de Ciências Sociais e de Geografia.

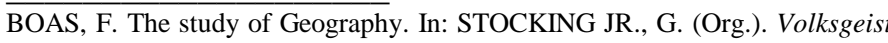
as method and ethic. Essays on Boasian Ethnography and the German Anthropological Tradition. Madison: The University of Wisconsin Press, 1996.

D'ANGLURE, B. S. Les masques de Boas: Franz Boas et l'ethnographie des Inuit. In: Études/Inuit/Studies, vol.8, 1984.

KOELSCH, W. A. Franz Boas geographer and the problem of disciplinary identity. In: Journal of the History of Behavioral Sciences, vol.40, 2004.

KUPER, A. The invention of primitive society: transformations of a illusion. New York: Routledge, 2005

MÜLLER-WILLE, Ludger. The Franz Boas enigma. Inuit, Arctic and sciences. Montreal: Baraka Books, 2014

RATZEL, F. Geografia dell'uomo (Antropogeografia). Torino: Fratelli Bocca 1914.

SPETH, W. W. The anthropogeographic theory of Franz Boas. In: Anthropos, vol.73, 1978 .

STOCKING JR., G. Race, Culture and Evolution. New York: The free Press, 1968. 